\title{
Micro method for manual analysis of true glucose in plasma without deproteinization
}

\author{
B. B. BAUMINGER \\ From the Department of Chemical Pathology, Bristol Royal Infirmary, Bristol
}

SYNOPSIS A sensitive micro method for the manual estimation of true glucose in $10 \mu l$ plasma by an enzymatic technique is described. Protein precipitation is avoided.

The method is simple to perform, accurate and precise. Agreement with a glucose oxidase autoanalyzer method is excellent, even with haemolysed and icteric specimens.

Although most estimations of blood glucose are now performed by automated methods, a need remains for occasional manual analyses on small samples of blood, particularly in paediatric practice. Ideally, the latter should employ a method which gives results identical with those obtained by the automated routine method, which is most likely to be achieved if the chemistry of both methods is the same.

The automated method employing glucose oxidase described by Trinder (1969a) is highly specific and, after minor modifications to the reagents, was found to be the most accurate and reliable of a number of currently available autoanalyzer methods for glucose estimation when compared with a gas-liquid chromatography reference method (Pennock, Murphy, Seller, and Longdon, 1973). A corresponding manual method by Trinder (1969b), however, requires $100 \mu \mathrm{l}$ sample, a different colour reagent from the autoanalyser method, and includes protein precipitation. This method has been modified so that a $10-\mu 1$ sample is sufficient and protein precipitation is avoided. Moreover, the reagents are exactly the same as in the modified Trinder automated procedure (Pennock et al, 1973).

\section{Method}

\section{REAGENTS}

\section{Phenol reagent}

$21.25 \mathrm{mM}$ phenol in $0 \cdot 154 \mathrm{M}$ sodium chloride solution ${ }^{1}$.

'For the automated method $1 \mathrm{ml}$ of Brij $35(25 \mathrm{~g} / \mathrm{dl})$ is added to 1 litre of $0.154 \mathrm{M}$ sodium chloride solution. This does not affect the micro manual procedure and can be omitted if the glucose oxidase method is not used for the autoanalyzer.

Received for publication 23 September 1974.

\section{Enzyme reagent}

Fermcozyme, $15 \mathrm{ml}, 15 \mathrm{mg}$ peroxidase, and $1.48 \mathrm{mM}$ 4-aminophenazone in $0.1 \mathrm{M}$ sodium acetate/acetic acid buffer at pH 6.0 . It is kept at $4^{\circ}$.

\section{Stock glucose solution}

$100 \mathrm{mmol} / \mathrm{l}, 18.02 \mathrm{~g}$ of glucose in 1 litre distilled water saturated with benzoic acid (0.024 M)

\section{Standard glucose solutions}

Diluted from stock solution using distilled water saturated with benzoic acid to the following concentrations: $0.5,1.0,2.5,5.0,10.0$, and $15 \mathrm{mmol}$ glucose/1

\section{PROCEDURE}

\section{Sample, standards, and reagent blank}

Deliver $10 \mu$ l of plasma, standards, or distilled water into a series of small tubes. Add to each tube $550 \mu l$ of phenol reagent, mix well, and then add $550 \mu \mathrm{l}$ of enzyme reagent and shake the tubes.

\section{Plasma blank}

To $10 \mu \mathrm{l}$ of plasma add $1.1 \mathrm{ml}$ of phenol reagent and mix well.

Place all tubes in a water bath at $45^{\circ}$ for 20 minutes. Shake the tubes briefly two or three times during incubation to ensure adequate aeration. Cool immediately to room temperature by standing in cold water, shake each tube, and measure the absorbence at $510 \mathrm{~nm}$. Subtract the absorbence readings of the plasma blank and reagent blank from those of the tests.

For freshly prepared solutions the reagent blank should have an absorbence not exceeding 0.01. 
CALCULATION

The graph relating absorbence to glucose concentration is linear through the origin.

Glucose concentration $=$

$$
\frac{\text { A*Test }- \text { Aplasma blank }- \text { AReagent blank }}{\text { Astandard }-A_{\text {Reagent blank }}} \times
$$

Concentration of standard .

* $\mathrm{A}$ = absorbence

\section{Experiments and Results}

A Pye Unicam SP 600 spectrophotometer with SP 680 micro cell accessory was used in the following experiments:

1 PROPERTIES OF THE COLOUR REACTION Colour development is maximal after 20 minutes' incubation at $45^{\circ}$. Higher absorbences are obtained at this temperature than at $37^{\circ}$; the former temperature was therefore adopted. The colour is stable at room temperature for at least 60 minutes and maximal absorption occurs at $510 \mathrm{~nm}$.

\section{PRECISION}

The within-batch precision of the proposed micro method was calculated from 12 determinations of glucose on each of three different plasma specimens. The results are summarized in table $I$ and indicate that the proposed method has good precision.

In recovery experiments a known amount of glucose was added to plasma and recoveries ranging from 96 to $98 \%$ were obtained.

\begin{tabular}{lll}
\hline Sample & $\begin{array}{l}\text { Mean } \\
(\text { mmol glucose/l) }\end{array}$ & $\begin{array}{l}\text { Coefficient of Variation } \\
(\%)\end{array}$ \\
\hline $1(\mathrm{n}=12)^{1}$ & $1 \cdot 71$ & $2 \cdot 34$ \\
$2(\mathrm{n}=12)$ & $3 \cdot 13$ & $0 \cdot 76$ \\
$3(\mathrm{n}=12)$ & $5 \cdot 51$ & 1.03 \\
\hline
\end{tabular}

Table I Precision (within batch) of plasma glucose estimation

${ }^{1} \mathbf{n}=$ no. of analyses

3 COMPARISON OF THE PROPOSED METHOD WITH THE STANDARD AUTOANALYZER PROCEDURE

When the manual micro method was compared with the autoanalyzer method samples were analysed by both methods on the same day so that deterioration of samples on storage should not influence the results.

Fifty-nine samples of plasma were analysed by both methods and the results are shown in the figure.

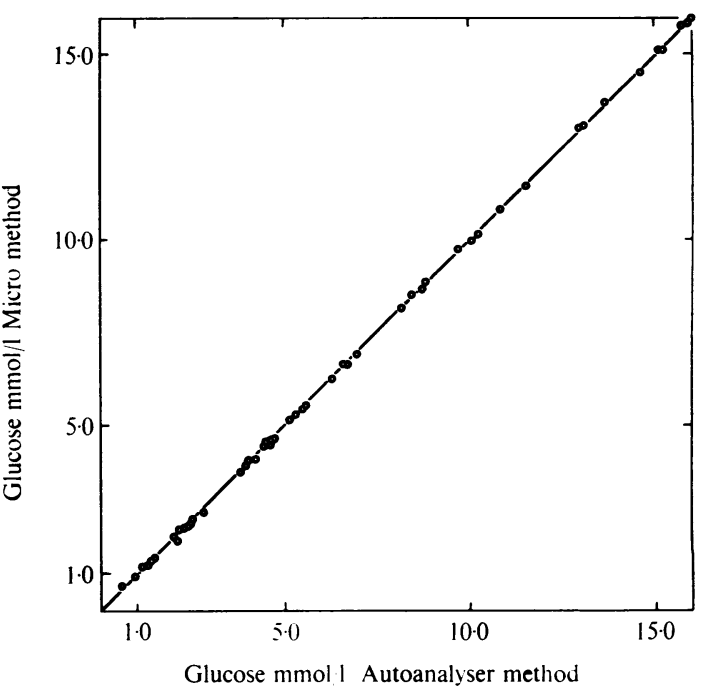

Fig Comparison of results obtained by the nsicro method with those of the autoanalyzer method.

The correlation coefficient was 0.9999 and the line of best fit $y=0.9989 x-0.0291$, where $x=$ autoanalyzer method and $y=$ micro manual method.

\section{EFFECT OF BILIRUBIN}

The glucose content of a sample of Versatol paediatric containing $342 \mu \mathrm{mol}$ bilirubin/l and $1.89 \mathrm{mmol}$ glucose/l was found to be 1.84 and $1.82 \mathrm{mmol}$ glucose/ 1 by the micro manual method and autoanalyser method respectively.

\begin{tabular}{|c|c|c|}
\hline \multirow[t]{2}{*}{ Plasma No. } & \multicolumn{2}{|l|}{ mmol Glucose/l Plasma ${ }^{1}$} \\
\hline & Micro Manual Method & Autoanalyzer Method \\
\hline 1 & 4.65 & $4 \cdot 58$ \\
\hline 2 & 2.05 & 2.00 \\
\hline 3 & $2 \cdot 66$ & 2.74 \\
\hline 4 & 4.58 & $4 \cdot 61$ \\
\hline 5 & 8.71 & 8.77 \\
\hline 6 & 4.07 & 3.99 \\
\hline 7 & 1.42 & 1.44 \\
\hline 8 & 1.39 & 1.39 \\
\hline 9 & 3.84 & 3.83 \\
\hline 10 & $4 \cdot 52$ & $4 \cdot 50$ \\
\hline 11 & $10 \cdot 20$ & $10 \cdot 21$ \\
\hline 12 & $13 \cdot 76$ & $13 \cdot 76$ \\
\hline 13 & 2.43 & $2 \cdot 50$ \\
\hline 14 & 1.25 & $1 \cdot 28$ \\
\hline 15 & 4.04 & 3.99 \\
\hline 16 & $14 \cdot 18$ & $14 \cdot 26$ \\
\hline 17 & 16.01 & 15.98 \\
\hline 18 & $5 \cdot 50$ & 5.44 \\
\hline
\end{tabular}

Table II Effect of haemolysis on the estimation of glucose in plasma by the micro method and autoanalyzer method

${ }^{1}$ Averages of duplicate determinations 
5 EFFECT OF HAEMOLYSIS

Preliminary experiments showed that haemolysis and bilirubin interfere with the determination of glucose. This is eliminated by including a plasma blank.

The absorbence of the plasma blank in a series of specimens showing haemolysis varied from 0.015 to 0.04 measured with the Pye Unicam SP 600 spectrophotometer, corresponding to glucose concentrations of 0.42 to $1.11 \mathrm{mmol} / \mathrm{l}$. The results obtained for these specimens by the micro technique and autoanalyzer method are given in table II. Agreement is excellent with a correiation coefficient of 0.999 .
I wish to thank Dr G. Walters for valuable suggestions. Thanks are also due to the staff of the automated section who analysed the samples by the autoanalyzer method.

\section{References}

Pennock, C. A., Murphy, D., Seller, J., and Longdon, K. J. (1973). A comparison of autoanalyser methods for the estimation of glucose in blood. Clin. chim. Acta, 48, 193-201.

Trinder, P. (1969a). Determination of glucose in blood using glucose oxidase with an alternative oxygen acceptor. Ann. clin. Biochem., 6, 24-25.

Trinder, P. (1969b). Determinations of blood glucose using 4-aminophenazone as oxygen acceptor. J. clin. Path., 22, 246. 